of Federal aid is needed, and a recent decision of the United States Supreme Court recognizes the right of Negroes to "proper provision" of graduate and professional study. So the States must provide separate facilities for them, or admit them to their universities.

\section{Amendments to the Therapeutic Substances Act}

TrE Joint Committee which administers the Therapeutic Substances Act, 1925, has issued some amending regulations (Statutory Rules and Orders, 1939, No. 1395. H.M. Stationery Office. 2d. net). A new regulation requires that every holder of a licence to manufacture therapeutic substances, who engages in the culture or manipulation of pathogenic sporo-bearing micro-organisnus, shall provide soparate laboratories, utensils and apparatus required for the culture or manipulation of such micro-organisms. New regulations aro also imposed respecting the labelling, testing and standardization of tetanus toxoid and gas gangrene antitoxin.

\section{Earthquake in Turkey}

For the second time recently Turkey has been stricken by a disastrous earthquake. On September 22, the epicentre was near Smyrna (Nature, September 30 , p. 589). Now, on the morning of November 23 , an intense shock destroyed at least six villages in Anatolia. Eighteen people aro known to have been killed, but complete news is not yet available since telegraphic and other communications were interrupted by the earthquake.

\section{The Night Sky in December}

ON December 22 at $18 \mathrm{~h}$. the sun enters the sign Capricornus (the winter solstice). In the latitude of London, the night then lasts for $16 \frac{1}{4}$ hours. The moon is new on December 10 and full on December 16. Lunar conjunctions with the planets occur as follows : on December 9d. 10h. with Mercury; 13d. Ih. with Venus ; 18d. 10h. with Mars ; 19d. 8 h. with Jupiter ; and on 2ld. 8h. with Saturn. The geocentric distance between moon and Mercury at conjunction on December 9 is only $0 \cdot 2^{\circ}$. Mars, Jupiter and Saturn south at about $17 \frac{1}{2} \mathrm{~h} ., 18 \frac{1}{2} \mathrm{~h}$. and $20 \mathrm{~h}$. respectively in mid-December and are therefore well placed for observation in the ovening sky. Venus is also coming into visibility as an evening star and may be seen low in the south-west after sunset. Mercury is at greatest elongation $\left(21^{\circ} \mathrm{WV}.\right)$ on December 17 , and it may then bo seen low down in the south-east before sunrise. In the late evenings of this month, there is a fine array of stars between the eastern horizon and the meridian. The variable star, Algol ( $\beta$ Persei), souths at about $21 \frac{1}{2} \mathrm{~h}$. in mid-December. Its change of light is most easily noticeable about $1 \frac{1}{2}$ hours before and after the following epochs : December 4d. 4.8h.; 7d. I.7h.; 9d. 22.5h.; 12d. $19 \cdot 3 \mathrm{~h}$.; 15d. $16 \cdot 1 \mathrm{~h}$. ; 27 d. $3 \cdot 4 \mathrm{~h}$. and $30 \mathrm{~d} .0 \cdot 2 \mathrm{~h}$. To the east of Algol, spread over an area of about $2^{\circ}$ in diameter, is a cluster of about five hundred remote stellar systems. A member of another cluster in Gemini, for which a spectrogram was secured at the Mt. Wilson Observatory, shows a redward shift of the spectral lines equivalent to a speed of recession from the solar system of more than 14,000 miles per second and indicating $\Omega$ distance of 135 million light years. The Geminid meteors, with their greatest frequency about December 10-12, have a radiant point a few degrees preceding Castor. At midnight on December 31 , the brightest star, Sirius (mag. - $1 \cdot 6$ ), is $4 \frac{1}{2} \mathrm{~min}$. past the southern meridian.

\section{Announcements}

Ix view of the delay likely to be caused by postal difficulties in the present circumstances, writers of "Letters" submitted for publication in the correspondence columns are advised that, in general, proofs of communications will not be sent to authors outside Great Britain.

Dr. Germard DowaGk, who was recently awarded the Nobel Prize for Physiology and Medicine for 1939, has been elected an honorary member of the Pharmaceutical Association of the Hindu University of Benares.

Dr. JUan Jacobo Spangenberg has been nom. inated president of the National Department of Health of the Argentine Republic in succession to Dr. Miguel Sussieri, who has retired.

Tine King has been pleased to grant Dr. Herbert Chatley his authority to wear the insignia of the Order of the Brilliant Jade conferred upon him by the President of the National Government of the Republic of China, in recognition of valuable services rendered by him as engineer-in-chief of the Whangpoo Conservancy Board.

Prof. Douglas McCanduish, of the Department of Leather Industries of the University of Leeds, has been appointed honorary director, and Mr. W. R. Atkin honorary research assistant, of the Procter International Research Laboratory.

The Bradshaw Lecture of the Royal College of Surgeons of England will bo delivered at the College in Lincoln's Inn Fields by Sir James Walton, on December 14 at 3.30 p.m. The subject of the lecture will be "The Surgery of the Common Bile Duct".

A LEaGue against syphilis and other venereal diseases has been founded in Cuba under the auspices of the Cuban National Institute of Social Welfare.

Tine Central International Seismological Bureau has removed from Strasbourg to 9 , boulevard de la Pyramide, Clermont:Ferrand, France, from which address it will continue to function as hitherto.

Ax Elgar scholarship in naval architecture of the value of $£ 130$ per annum for three or four years is now being offered. Fntries close on January 15, 1940. Full particulars may be obtained from the Secretary of the Institution of Naval Architects, 10 Upper Belgrave Street, I.ondon, S.IW.I. 